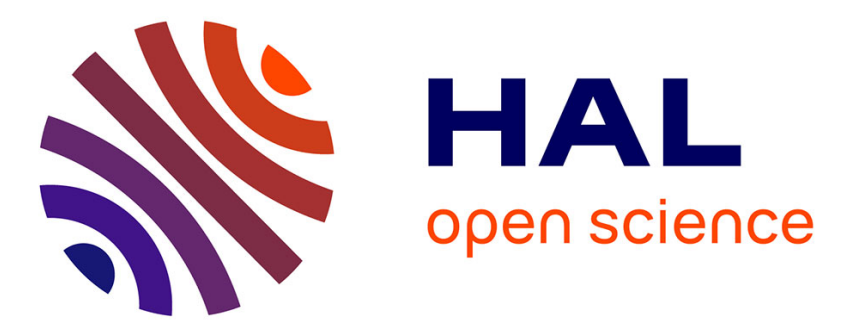

\title{
Contributions of internal hydrogen and room-temperature creep to the abnormal fatigue cracking of Ti6246 at high Kmax
}

Frédéric Mignot, Véronique Doquet, Christine Sarrazin-Baudoux

\section{- To cite this version:}

Frédéric Mignot, Véronique Doquet, Christine Sarrazin-Baudoux. Contributions of internal hydrogen and room-temperature creep to the abnormal fatigue cracking of Ti6246 at high Kmax. Materials Science and Engineering: A, 2004, 380 (1-2), pp.308-319. 10.1016/j.msea.2004.04.006 . hal-00111412

\author{
HAL Id: hal-00111412 \\ https://hal.science/hal-00111412
}

Submitted on 9 Jul 2019

HAL is a multi-disciplinary open access archive for the deposit and dissemination of scientific research documents, whether they are published or not. The documents may come from teaching and research institutions in France or abroad, or from public or private research centers.
L'archive ouverte pluridisciplinaire HAL, est destinée au dépôt et à la diffusion de documents scientifiques de niveau recherche, publiés ou non, émanant des établissements d'enseignement et de recherche français ou étrangers, des laboratoires publics ou privés. 


\title{
Contributions of internal hydrogen and room-temperature creep to the abnormal fatigue cracking of Ti6246 at high $K_{\max }$
}

\author{
F. Mignot $^{\mathrm{a}}$, V. Doquet ${ }^{\mathrm{a}, *}$, C. Sarrazin-Baudoux ${ }^{\mathrm{b}}$ \\ ${ }^{a}$ Laboratoire de Mécanique des Solides, UMR CNRS 7649, Ecole Polytechnique, 91128 Palaiseau Cedex, France \\ ${ }^{\mathrm{b}}$ Laboratoire de Mécanique et Physique des Matériaux, UMR CNRS 6617, ENSMA, 86961 Futuroscope Cedex, France
}

\begin{abstract}
This study aims at explaining the absence of a threshold for crack propagation in an $\alpha / \beta$ titanium alloy during cyclic tests performed with constant $K_{\max }$ and increasing $K_{\min }$, if $K_{\max }$ is higher than 60-70\% of $K_{\mathrm{Ic}}$. Tensile, creep as well as fatigue crack growth tests are performed on specimens with various hydrogen content. SIMS analyses of hydrogen content around the tip of a crack developed in the abnormal regime are made. Solute hydrogen is shown to segregate at the crack tip and to enhance room-temperature creep, strain localisation and decohesion along $\alpha / \beta$ interfaces.
\end{abstract}

Keywords: Titanium; Hydrogen; Creep; Cracking; Fatigue threshold

\section{Introduction}

Tests with decreasing $\Delta K$ performed with constant maximum stress intensity factor, $K_{\max }$ and increasing $K_{\min }$ (Fig. 1) tend to supersede tests with constant $R=K_{\min } / K_{\max }$ to determine the fatigue crack propagation threshold of a material. With the new procedure, if $K_{\max }$ is high enough for $K_{\min }$ to be above $K_{\text {opening }}$ at threshold, closure effects no longer impede the determination of the effective threshold for fatigue crack growth [1]. Furthermore, for the titanium alloys used in aeronautical rotor disks, this type of loading mimics in-flight loading, characterised by small fluctuations around a high mean stress [2].

Unfortunately, for $K_{\max }$ higher than $60-70 \%$ of $K_{\mathrm{Ic}}$, an abnormal behaviour was observed, in several dual-phase titanium alloys [3-5], which include Ti6246. As $\Delta K$ decreases, the crack growth rate does not decrease or drop below $10^{-11} \mathrm{~m} /$ cycle as expected, but reaches an asymptotic value dependent only on $K_{\max }$. In other words, there is no threshold for fatigue crack propagation at high $K_{\max }$. In the case of Ti6246, the abnormal regime is observed in air (Fig. 2a) as

\footnotetext{
* Corresponding author. Tel.: +33-1-69-33-33-55; fax: +33-1-69-33-30-26.

E-mail address: doquet@1ms.polytechnique.fr (V. Doquet).
}

well as under secondary vacuum, at room temperature. Thus, the abnormal cracking is not related to the environment.

Lang [5] considers that the disappearance of the fatigue crack growth threshold at high $K_{\max }$ in titanium alloys is not an unknown phenomenon but just a form of sustained load cracking (SLC). In the Ti6246 of the present study, the minimum $K_{\max }$ for abnormal cracking under cyclic loading is just slightly above the threshold for SLC, $K_{\text {ISLC }}=$ $49 \mathrm{MPa} \mathrm{m}^{1 / 2}$. When after cyclic loading at high $K_{\max }, K$ is suddenly fixed at $K_{\max }$, the crack stops. Then, after an incubation period, which decreases with the last $\Delta K$ applied (Fig. 2b), crack propagation resumes and the growth rate in SLC is similar to the asymptotic growth rate in fatigue in terms of $\mathrm{d} a / \mathrm{d} t=f \mathrm{~d} a / \mathrm{d} N$. But the mechanisms of SLC in titanium alloys remain unclear and two different explanations have been put forward.

In the literature on the subject, the SLC of titanium alloys [6-8] has sometimes been related to their propensity for low-temperature creep [9-14]. Tests performed on Ti6246 at $f=35$ and $3.5 \mathrm{~Hz}$ at $20^{\circ} \mathrm{C}$ show that the asymptotic growth rate in the abnormal regime is approximately 10 times higher in the latter case, which suggests a time-controlled phenomenon like creep, since $\mathrm{d} a / \mathrm{d} t$ is quasi-identical in both cases (Fig. 2c). The fact that the abnormal cracking regime disappears at intermediate temperatures-a threshold was found at $150^{\circ} \mathrm{C}$, at high $K_{\max }$-while it is observed 


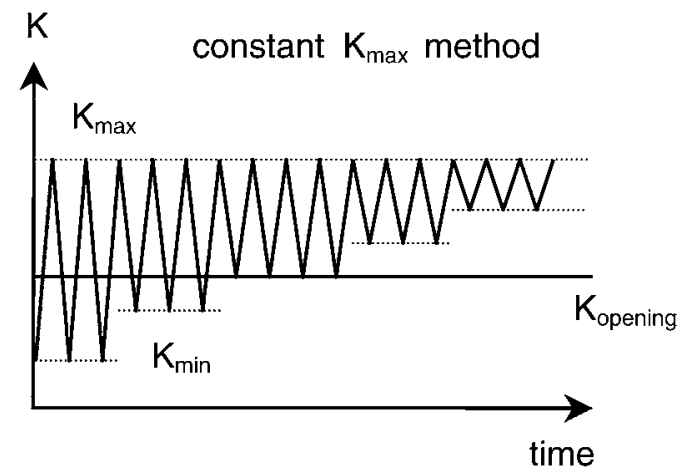

Fig. 1. Constant $K_{\max }$ procedure for the measurement of the threshold for fatigue crack growth.

at $500^{\circ} \mathrm{C}$, although with an asymptotic growth rate one decade smaller than at $20^{\circ} \mathrm{C}$ (Fig. 2a), does not rule out an explanation based on creep, since creep does not necessarily increase with temperature in titanium alloys (see, for example, [9] or [15]) partly because of dynamic strain ageing phenomena (DSA) [15-19].

But SLC in titanium alloys has also been related to hydrogen "embrittlement" (internal hydrogen is believed to concentrate at the crack tip where the hydrostatic tension is high). Shih et al. [20] have shown that hydrogen can either promote localised plastic deformation at a crack tip, in $\alpha$ titanium, or trigger crack propagation through repeated nucleation and fracture of brittle hydrides ahead of the tip. In the present problem, decohesions along $\alpha / \beta$ interfaces observed on the fracture surfaces in the abnormal cracking regime [2,3] may be a sign of hydrogen "embrittlement", that is: H-enhanced localised plastic deformation or fracture of hydride precipitates.

Anyway, no direct proof has yet been given that either explanation (creep and/or hydrogen effects) is correct. That is why the present investigation was undertaken.

\section{Experimental study}

\subsection{Material and experimental procedures}

The Ti6246 alloy investigated (6wt.\% Al, 2 wt.\% Sn, $4 \mathrm{wt} . \% \mathrm{Zr}, 6 \mathrm{wt} . \% \mathrm{Mo}$ ) is constituted of primary $\alpha$ (hcp) platelets (denoted by $\alpha_{p}$ on Fig. 3), approximately 1-2 $\mu \mathrm{m}$ wide and $10-30 \mu \mathrm{m}$ long, embedded in a partially transformed $\beta$ (bcc) matrix containing small secondary $\alpha$-laths (denoted by $\alpha_{\mathrm{s}}$ ), a few nanometres long. The total fraction of $\alpha$-phase is about $75 \%$. The diameter of former $\beta$-grains is $300-400 \mu \mathrm{m}$. The comparison of the macro-texture (measured by X-ray diffraction) and local textures (measured by electron back scattering diffraction in the SEM) shows that pole figures obtained over one $\beta$-grain are already almost similar to average pole figures and do not change much from one $\beta$-grain to another [21]. A majority of $\alpha$-laths have their $c$-axis inclined by $50^{\circ}$ or more to the specimens axis. The interstitial solutes mass content of the material is: 40-85 ppmw H, 1000 ppmw O and 40 ppmw N. The yield stress is $860 \mathrm{MPa}$, the ultimate strength $1260 \mathrm{MPa}$ and the toughness $K_{\text {Ic }}=75 \pm 5 \mathrm{MPa} \mathrm{m}^{1 / 2}$. Note that the solubility of hydrogen in the $\alpha$-phase is less than $40 \mathrm{ppmw}$ at $20^{\circ} \mathrm{C}$ and around $2 \%$ in the $\beta$-phase [22]. The hydrogen diffusivity is also much higher in the latter. The yield stress in the $\beta$-phase is substantially higher than in the $\alpha$-phase [23]. In addition, plastic deformation is limited in the transformed $\beta$-matrix as well as in secondary $\alpha$-laths by small mean free paths.

Six millimetre thick compact tension (CT) and $3 \mathrm{~mm}$ thick compact tension-shear (CTS) specimens as well as flat tensile/creep specimens with a $1 \mathrm{~mm} \times 4 \mathrm{~mm}$ cross-section were cut from a helicopter compressor disk. Several heat treatments at 400 or $500{ }^{\circ} \mathrm{C}$ under secondary vacuum, or under argon $+10 \%$ hydrogen flux, or in pure $\mathrm{H}_{2}$, were applied to decrease or increase the solute hydrogen content, which was determined through analyses of the gas released by small melted probes. Extensive transmission electron microscopic (TEM) observations were made to check that none of these treatments altered the microstructure (size and proportion of primary and secondary $\alpha$-laths) at least up to 800 ppmw hydrogen. The oxygen and nitrogen content was also checked to be unchanged.

Tensile and CTS specimens are covered with gold microgrids ( $4 \mu \mathrm{m}$ pitch) and some of the tests are carried out using a machine performing in the chamber of a SEM, in order to identify microscopic mechanisms in relation with the microstructure. Correlation of high definition digital images $(4000 \times 4000$ pixels $)$ taken at several stages of a test yields the local displacement field and by derivation, the strain field. More details about this technique can be found in [24].

After precracking at decreasing $\Delta K$, fatigue crack growth tests are performed using conventional machines with a constant $K_{\max }$ and increasing $K_{\min }$, at 15 or $30 \mathrm{~Hz}$ (the crack length being monitored with an optical microscope and a dc potential drop device, also used to control the machine).

Secondary ions mass spectroscopy (SIMS) is suitable for light and trace elements analysis with a high spatial resolution. A CT specimen with a crack grown at high $K_{\max }$ into the abnormal regime was carefully sectioned at mid-thickness with a diamond saw and mechanically polished to allow SIMS analyses of the $\mathrm{H}$ content around the crack. An $\mathrm{O}_{2}{ }^{+}$ primary ion beam with an acceleration voltage of $20 \mathrm{kV}$ was used. Each measurement "point" corresponds to a volume of $8 \mu \mathrm{m}$ in diameter and approximately $1 \mu \mathrm{m}$ in depth. Data were recorded only when each probing zone had been sputtered for $3 \mathrm{~min}$ to remove any contamination layer (after this time, the measured signal was observed to reach a steady-state value). The number of $\mathrm{H}$ ions count per second was normalized by the intensity of the primary ion beam to take account of its small fluctuations in time. The $\mathrm{H}$ content of the unstrained material corresponds to an index of $250 \pm 20$. 


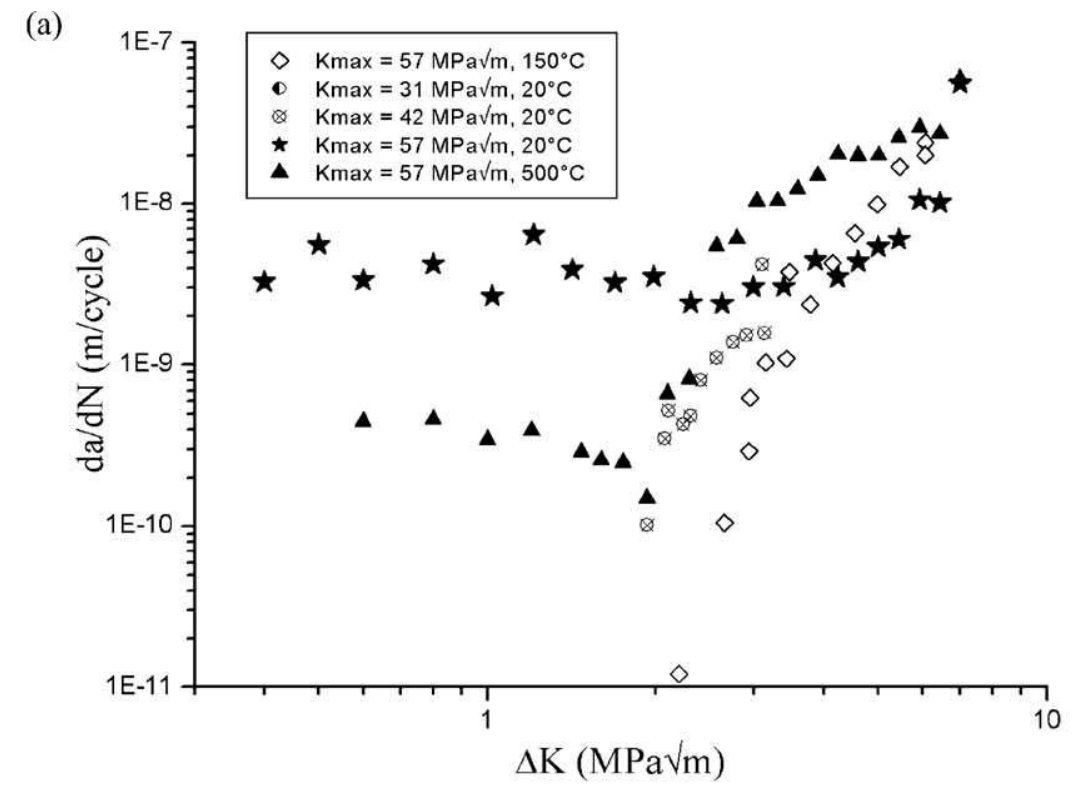

(b

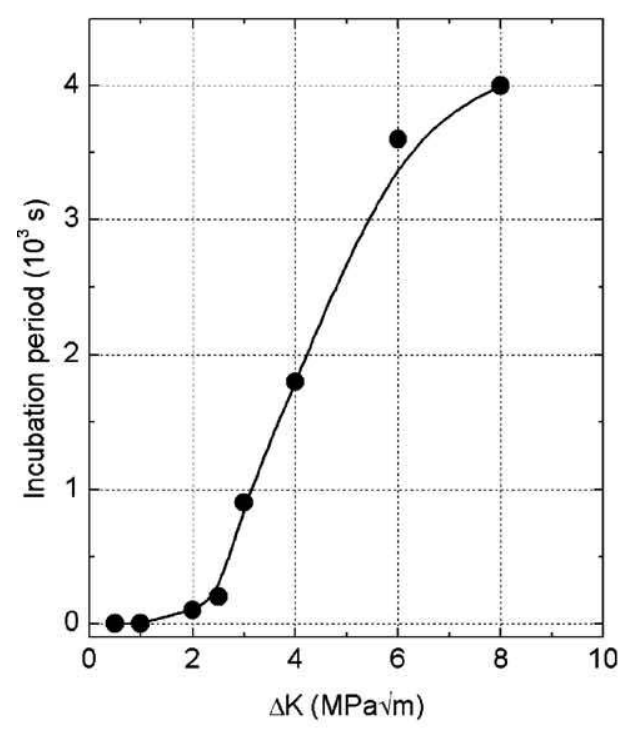

(c)

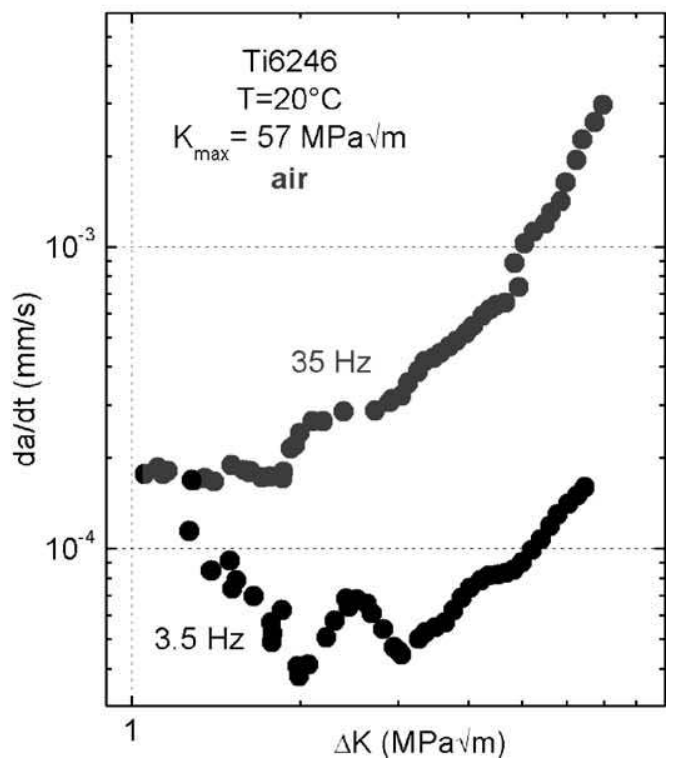

Fig. 2. (a) Crack growth kinetics in Ti6246 at constant $K_{\max }$, at 20,150 and $500^{\circ} \mathrm{C}$, in air. (b) Evolution of the incubation period for sustained load cracking at $K_{\max }$ after cyclic loading as a function of the amplitude $\Delta K$. (c) Influence of the test frequency on the crack growth kinetics (in terms of $\mathrm{d} a / \mathrm{d} t)$ at $20^{\circ} \mathrm{C}$.

\section{Results and discussion}

\subsection{Hydrogen concentration at the crack tip}

Fig. 4a shows the measured profile of the $\mathrm{H}$ concentration index along the ligament at mid-thickness of a CT specimen. The $\mathrm{H}$ content is increased by a factor of two at the crack tip and recovers its normal value at a distance of $1.5 \mathrm{~mm}$. Fig. $4 \mathrm{~b}$ is a map of the $\mathrm{H}$ concentration index along the crack flanks, near the transition point from the normal "Paris regime" $\left(\Delta K>3 \mathrm{MPa} \mathrm{m}^{1 / 2}\right)$ to the abnormal regime. While the colour contrast on the crack itself in the Paris regime should not be considered significant (it is probably due to some debris entrapped between the crack flanks that have a slight residual opening at high $\Delta K$ ), the white haze around the part grown in the abnormal regime reveals a $100 \mu \mathrm{m}$ wide zone enriched with $\mathrm{H}$.

This hydrogen concentration measured at the crack tip (twice the average) seems low compared to the enrichment corresponding to the stoichiometry of hydrides: $\mathrm{TiH}_{x}$ with $x$ between 1.5 and $2[22,25]$. Hydride precipitation at $20^{\circ} \mathrm{C}$, however, cannot be ruled out (such an explanation of the 


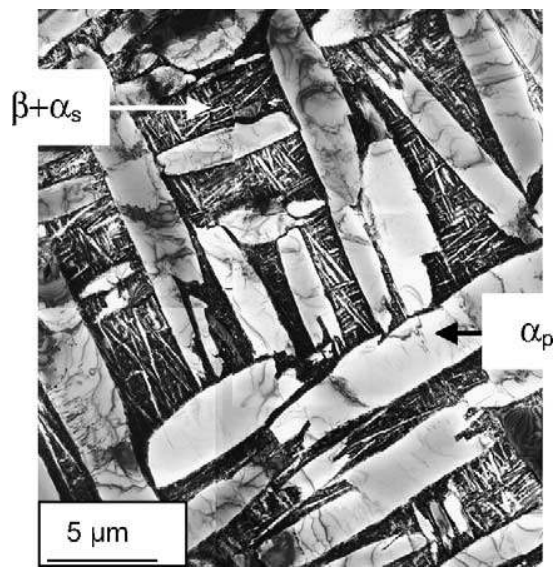

Fig. 3. Microstructure of Ti6246-TEM image ( $\alpha_{\mathrm{p}}$ and $\alpha_{\mathrm{s}}$ denote primary and secondary $\alpha$-laths, respectively).

abnormal cracking would be coherent with the absence of anomaly at $150^{\circ} \mathrm{C}$, a temperature for which the solubility of $\mathrm{H}$ in the $\alpha$-phase is 10 times higher than at $20^{\circ} \mathrm{C}$ ). It is not an easy task to determine through TEM observations whether or not hydrides form at a crack tip since the thin foils have to be cut extremely close to the tip (the H-rich zone seems to be only $100 \mu \mathrm{m}$ wide), where the density of dislocations is extremely high, due to the values of $K_{\max }$ in the abnormal cracking regime. But as it will be shown further, the influence of hydrogen in solid solution on the material behaviour is quite sufficient in itself to explain the abnormal cracking.

\subsection{Influence of hydrogen content on crack propagation at high $K_{\max }$}

Fig. 5 summarises the kinetic data obtained on CT and CTS specimens containing various amounts of hydrogen.

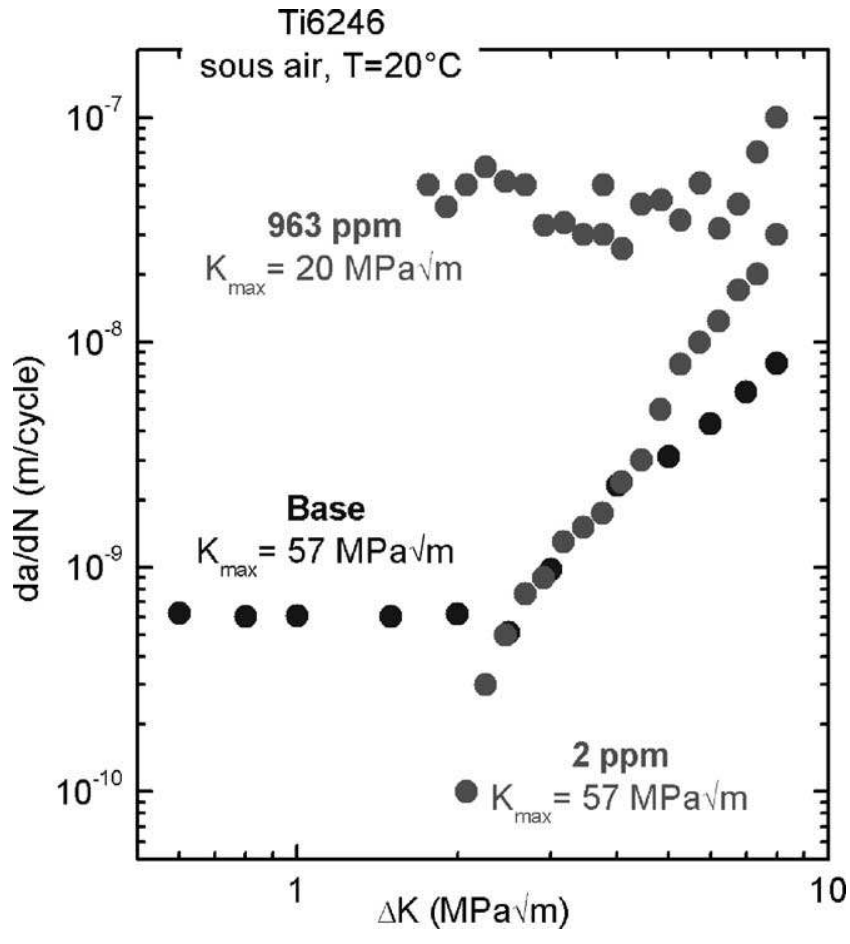

Fig. 5. Influence of the hydrogen content on the fatigue crack growth kinetics in Ti6246 at $20^{\circ} \mathrm{C}$.

A test performed on a CT specimen of base material with $K_{\max }=57 \mathrm{MPam}^{1 / 2}$ led to an asymptotic growth rate of $6 \times 10^{-10} \mathrm{~m} /$ cycle. A CTS specimen of base material was tested in the SEM. An increase in the crack opening was observed during a $5 \mathrm{~h}$ hold-time at $K_{\max }=57 \mathrm{MPam}^{1 / 2}$ (Fig. 6). This means that creep is present at the crack tip at room temperature in the base metal. The crack often follows $\alpha / \beta$ interfaces (Fig. 7a) and faceted zones appear on the fracture surface. The perfect matching of details on both fracture
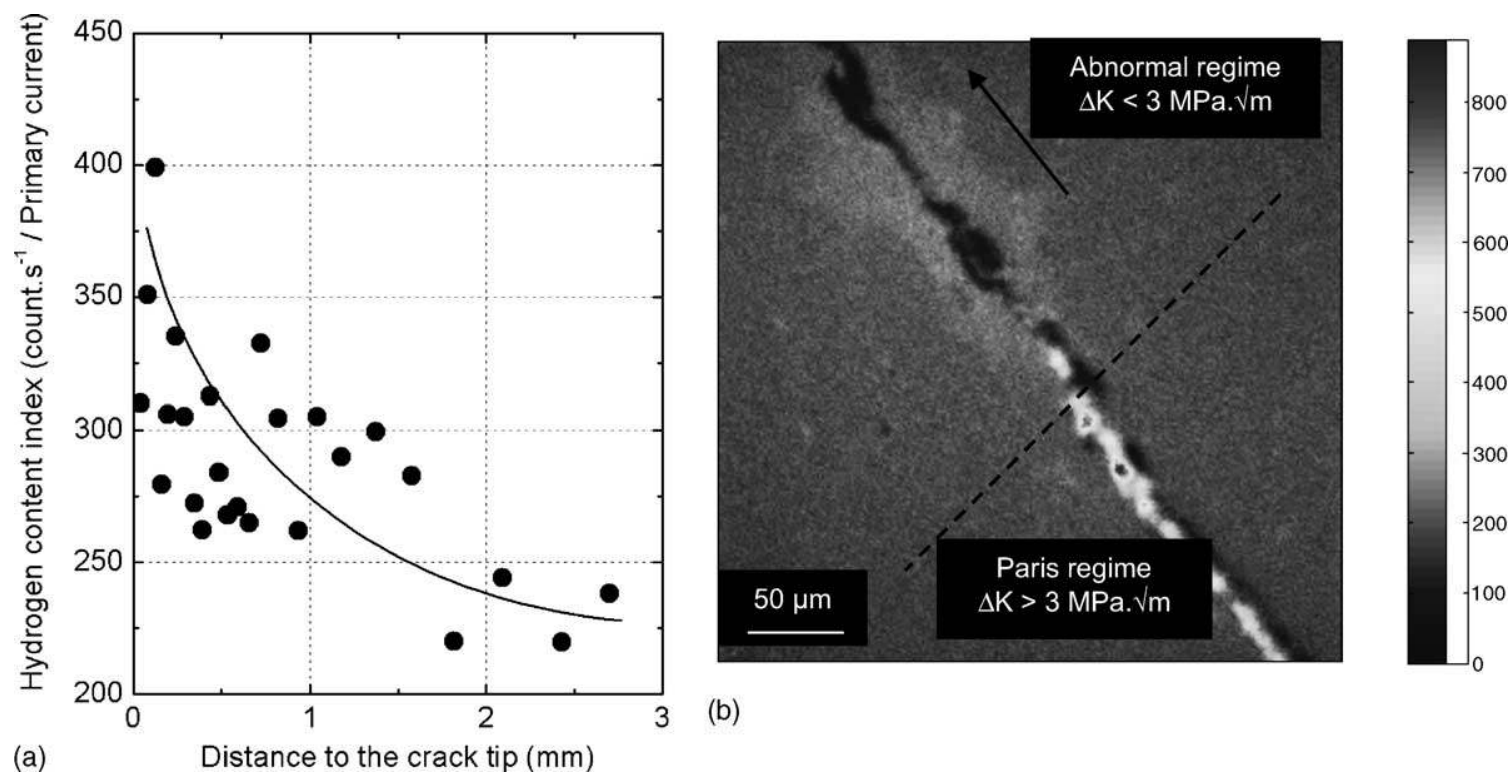

(b)

Fig. 4. SIMS analyses of hydrogen ahead (a) and around (b) a crack grown at $K_{\max }=57 \mathrm{MPa} \mathrm{m}^{1 / 2}$. 


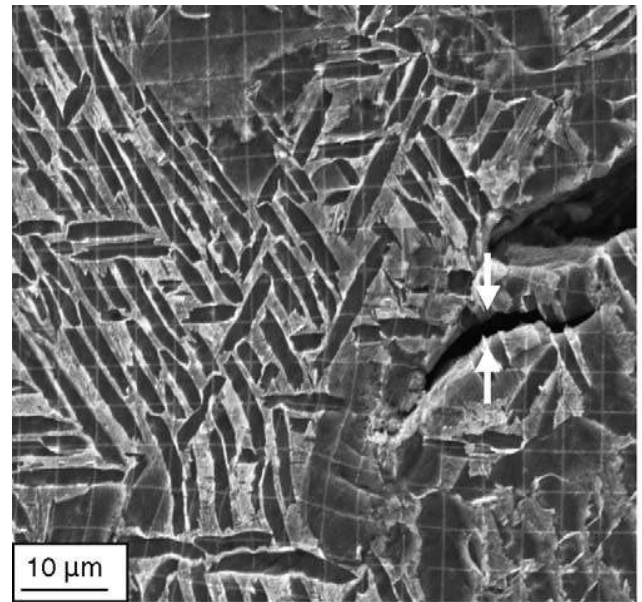

(a)

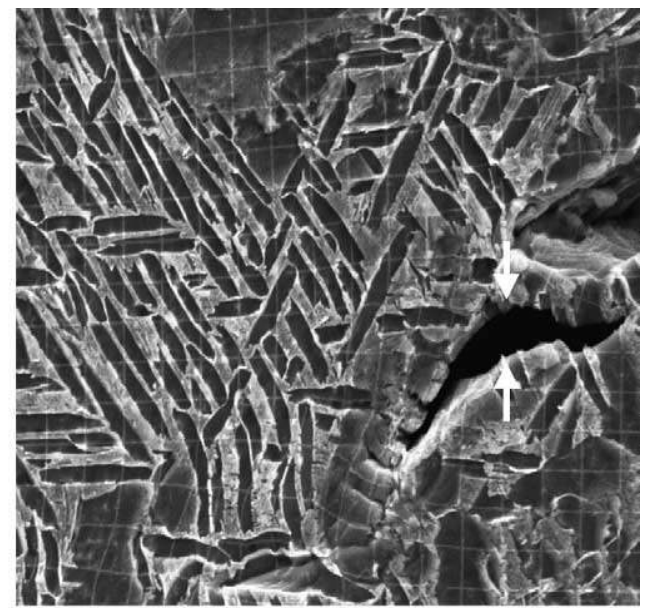

(b)

Fig. 6. (a) Crack growth test on the base metal in the SEM. (b) Evolution of crack tip opening displacement during a $5 \mathrm{~h}$ hold-time at $K_{\max }=57 \mathrm{MPa} \mathrm{m}^{1 / 2}$.

(a)

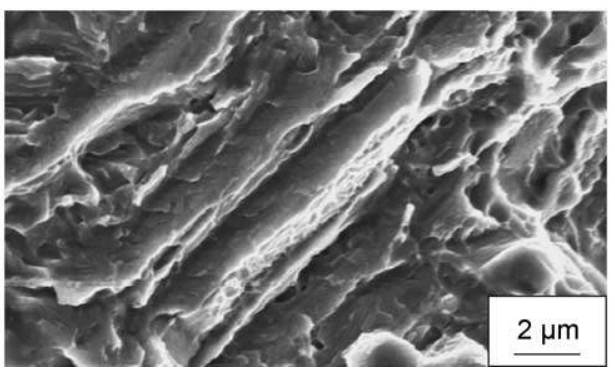

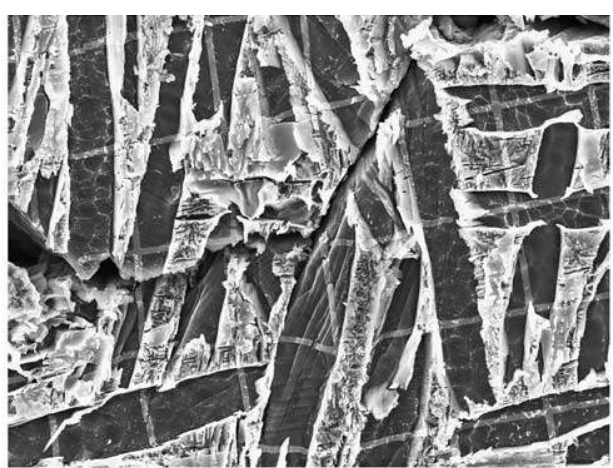

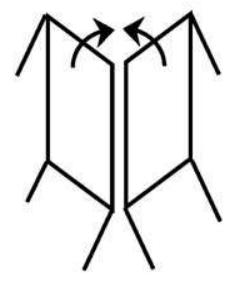

(c)

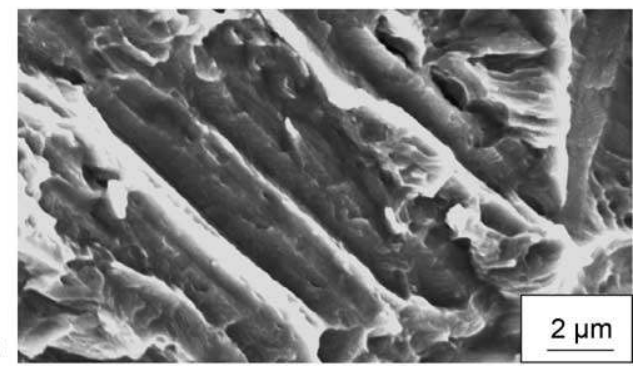

Fig. 7. (a) Damage process ahead of the crack tip in the base metal. (b and c) Perfect matching of details on both fracture surfaces in facetted zones.

surfaces (Fig. 7b and c) indicates a decohesion process (and not cavity growth like in flutting). However, a closer examination of Fig. 7a shows that localised slip bands parallel to the damaged $\alpha / \beta$ interfaces are present in the $\alpha$-laths. Ductile decohesion might have occurred along a localised slip band of the hcp phase very close to the interface.

A H-depressed CTS specimen (residual H: 2 ppmw) was tested successively at $K_{\max }=57,62$ and finally $67 \mathrm{MPa} \mathrm{m}^{1 / 2}$. All conditions gave rise to crack deceleration and arrest (Fig. 5). An unusual increase in threshold is observed as $K_{\max }$ increases. This is due to the development of shear lips when $K_{\max }$ becomes higher than $60 \mathrm{MPa} \mathrm{m}^{1 / 2}$ and to the dissipation of energy by friction of these shear lips. Comparisons of crack growth curves for various $\mathrm{H}$ content should thus be made only for similar $K_{\max }$. However, the comparison of the crack growth kinetics at $57 \mathrm{MPa} \mathrm{m}^{1 / 2}$ in base metal and in the degassed specimen shows that the removal of internal hydrogen has suppressed the abnormal cracking regime.

A CTS specimen charged up to 960 ppmw hydrogen was tested with $K_{\max }=20 \mathrm{MPam}^{1 / 2}$. A growth rate of $6 \times$ $10^{-8} \mathrm{~m} /$ cycle was obtained, which is two orders of magnitude more than the asymptotic growth rate measured at $57 \mathrm{MPa} \mathrm{m}^{1 / 2}$ in the base metal (Fig. 5).

A CTS specimen charged with hydrogen up to $850 \mathrm{ppm}$ was tested in the SEM. The crack tip blunted during the ramp up to $K_{\max }$ and grew into a shear band, $60^{\circ}$ from its initial direction (Fig. 8b). When cyclic loading at $\Delta K=2 \mathrm{MPa} \mathrm{m}^{1 / 2}$ 


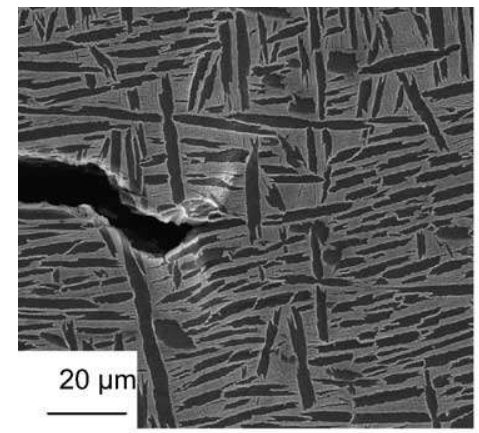

(a) $\mathrm{K}=40 \mathrm{MPa} \sqrt{\mathrm{m}}$

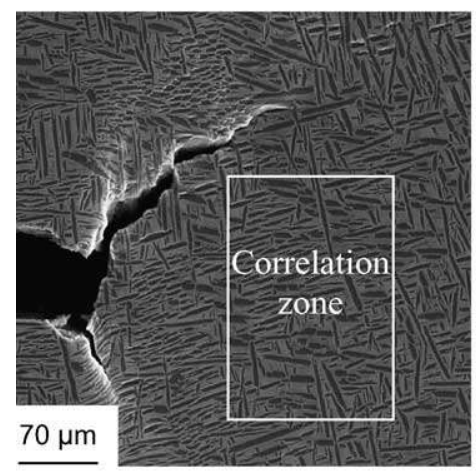

(c) $\mathrm{K}=57 \mathrm{MPa} \sqrt{\mathrm{m}}$

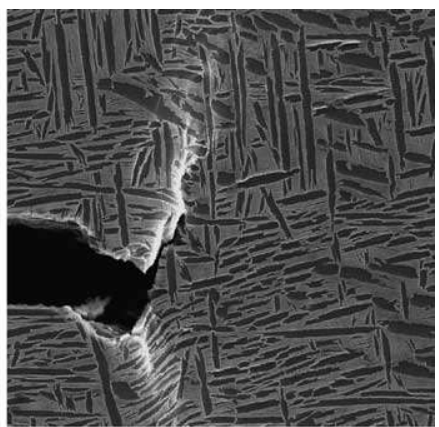

(b) $1 \mathrm{minhold}$ at $\mathrm{K}=40 \mathrm{MPa} \sqrt{\mathrm{m}}$

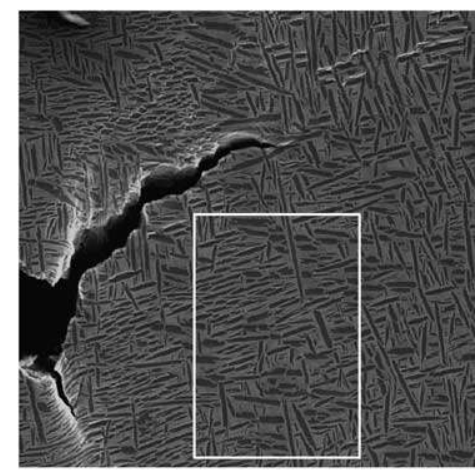

(d) $2 \mathrm{~min}$ hold at $\mathrm{K}=57 \mathrm{MPa} \sqrt{\mathrm{m}}$

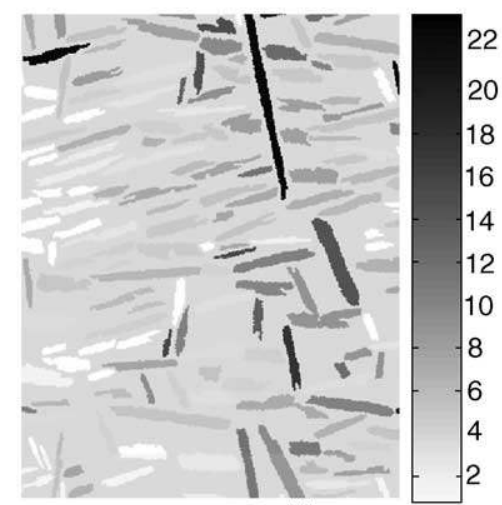

(e) Equivalent strain ${ }^{\mathrm{M}}(\%)$

Fig. 8. Test in the SEM on a CTS specimen charged at 850 ppmw H aspect of the crack tip: (a) $K=40 \mathrm{MPam}^{1 / 2}$; (b) 1 min hold at $K=40 \mathrm{MPa} \mathrm{m}^{1 / 2}$; (c) $K=57 \mathrm{MPa} \mathrm{m}^{1 / 2}$; (d) 2 min hold at $K=57 \mathrm{MPam}^{1 / 2}$. (e) Evolution of von Mises equivalent strain in the $\alpha$-laths within the correlation zone during a 2 min hold-time at $K_{\max }=57 \mathrm{MPa} \mathrm{m}^{1 / 2}$.

was started, the crack progressively returned to a direction normal to the tensile axis (Fig. 8c and d). Blunting of the crack and damage ahead of the tip, especially along $\alpha / \beta$ interfaces, were seen to increase during steady periods at $K_{\max }$ (compare Fig. 8a-d). During cycling, propagation proceeded by repeated coalescence of the main crack with more or less parallel microcracks, some distance ahead (Fig. 9a). Fig. 8e is a map of the von Mises equivalent strain variation (averaged in each in $\alpha$-lath) during a 2 min hold-time at $57 \mathrm{MPa} \mathrm{m}^{1 / 2}$ obtained by correlating the images (c) and (d) in the rectangular area ahead of the crack tip. The equivalent strain had increased substantially (up to $22 \%$ ) in some $\alpha$-laths. The strain map is smaller than a $\beta$-grain size, but if the observed creep was just an effect of local texture, it would be insufficient to blunt the crack tip so much during hold periods at constant $K_{\mathrm{I}}$ (remember that the specimen is $3 \mathrm{~mm}$ thick; if the crack remained sharp below the surface and if the material above and below the crack plane did not creep, it would resist opening at the surface). Furthermore, such an increase in blunting in the H-charged specimen has been observed repeatedly, when the crack tip was in different $\beta$-grains (see, for example, Fig. $8 \mathrm{~b}$ and c). Creep at the crack tip is thus extremely pronounced when hydrogen is added. Faceted decohesion zones similar to those already observed on the base metal are present on the fracture surface, but much more frequent (Fig. 9b). The out-of-plane relative 


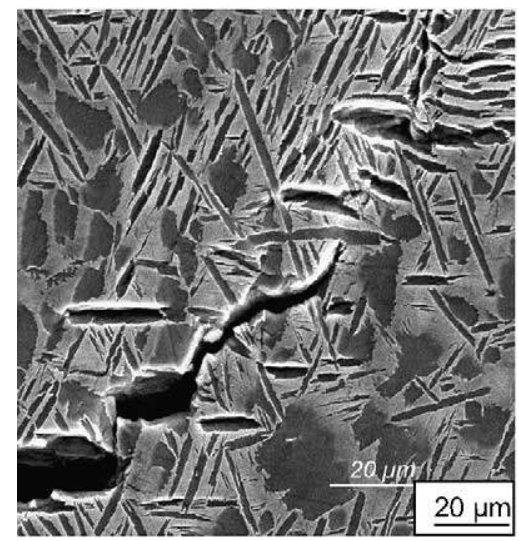

(a)

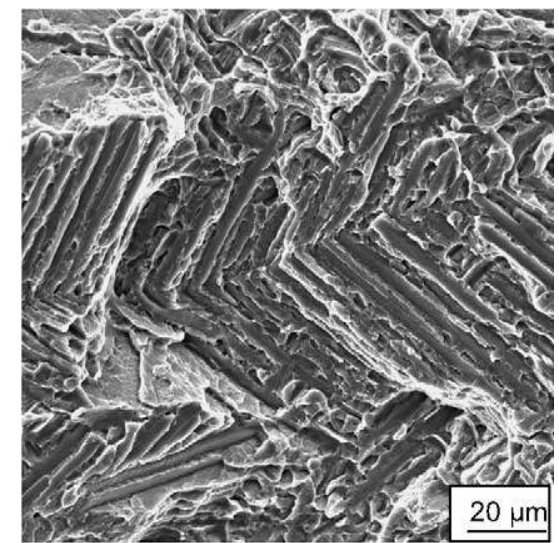

(b)

Fig. 9. Damage process ahead of the crack tip in a specimen charged at $850 \mathrm{ppm}$ : (a) damage in some $\alpha$-laths close to $\alpha / \beta$ interfaces; (b) large faceted zone on the fracture surface.

displacement associated with interfacial damage (Fig. 9a) seems coherent with ductile shear decohesion along facets inclined $45^{\circ}$ to the free surface rather than tensile brittle decohesion normal to the applied stress.

\subsection{Influence of the hydrogen content on the tensile behaviour}

Tensile tests performed at $20^{\circ} \mathrm{C}$ at a strain rate of $10^{-4} \mathrm{~s}^{-1}$ in the SEM show that the yield stress, hardening rate and "uniform" strain are not significantly modified by hydrogen, but that the total strain at fracture is almost doubled when the $\mathrm{H}$ content is around $500 \mathrm{ppmw}$ (Fig. 10). It recovers a value similar to that of the base metal, around $1100 \mathrm{ppmw}$.

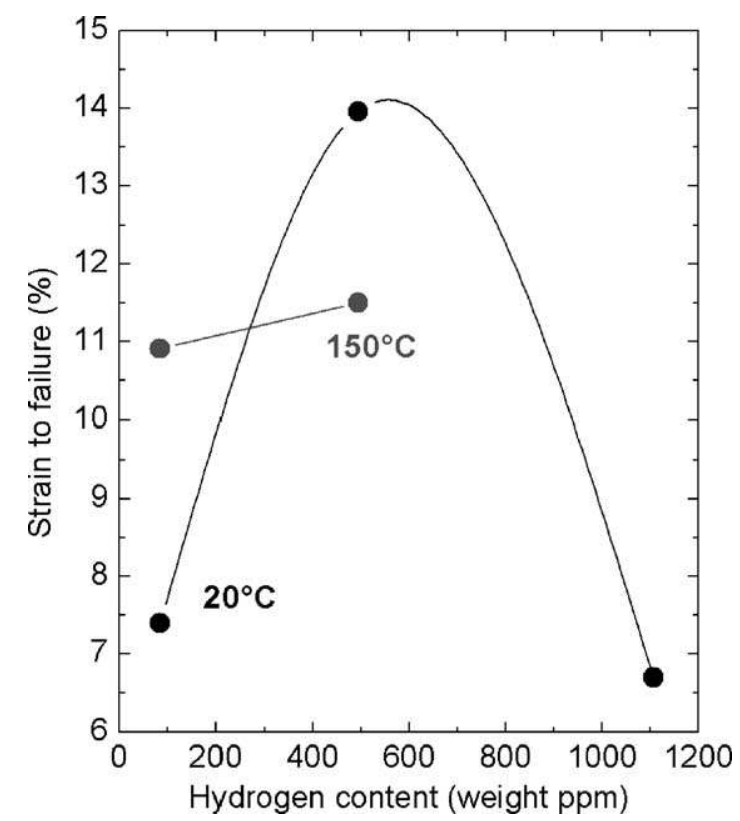

Fig. 10. Influence of the hydrogen content on the tensile properties of Ti6246 at 20 and $150^{\circ} \mathrm{C}$ : evolution of the total strain at fracture.
This suggests an increase in the strain rate sensitivity of the flow stress (and thus a decrease in the activation volume) when a moderate amount of hydrogen is added. Senkov and Jonas [18] reached the same conclusion for $\alpha$ titanium tested at temperatures between 500 and $700^{\circ} \mathrm{C}$.

SEM and TEM observations show that the base metal deforms through planar localised prismatic glide in $\alpha$-laths (Fig. 11). Slip localisation in this alloy has been related to dislocation shearing of tiny $\mathrm{Ti}_{3} \mathrm{Al}$ precipitates [26]. TEM observations failed to reveal the presence of such precipitates in our material, however, as suggested by Suri et al. [27], short-range ordering of $\mathrm{Ti}$ and $\mathrm{Al}$ atoms could also lead to localised slip in this material. The predominance of straight $\langle a\rangle$-type dislocation segments of screw character $(\langle a\rangle=(a / 2)\langle 11 \overline{2} 0\rangle)$ is a sign of large lattice friction on screw dislocations. Naka et al. [28], and more recently, Farenc et al. [29,30], have suggested that the core of $\langle a\rangle$-type screw dislocations is non-planar and their mobility is controlled by thermally activated constriction (see also [15] for a review). They explained that interstitials like oxygen, nitrogen and carbon make this constriction more difficult and thus harden $\alpha$ titanium substantially at low and medium temperatures.

The deformation mechanisms seem to be significantly modified when $\mathrm{H}$ is added. Fig. 13 shows the influence of the $\mathrm{H}$ content on the degree of strain localisation along $\alpha / \beta$ interfaces, at 20 and $150^{\circ} \mathrm{C}$ (Fig. 12). It was obtained by a systematic quantitative analysis of $500 \mu \mathrm{m} \times 500 \mu \mathrm{m}$ SEM images of deformed specimens. The percentage of $\alpha$-laths showing signs of interfacial glide (shift of microgrids) sharply increases with the $\mathrm{H}$ content. This is coherent with TEM observations, which suggest that $\alpha / \beta$ interfaces act as dislocation sources in $\mathrm{H}$-charged specimens.

Margolin [31] also reported some interfacial glide at room temperature in $\alpha / \beta$ titanium alloys and related this effect to $\mathrm{H}$ pickup during etching of specimens surfaces. He attributed interfacial sliding to either a $\mathrm{H}$ flux or $\mathrm{H}$ trapping at the interface, both causing local expansion and weakening 


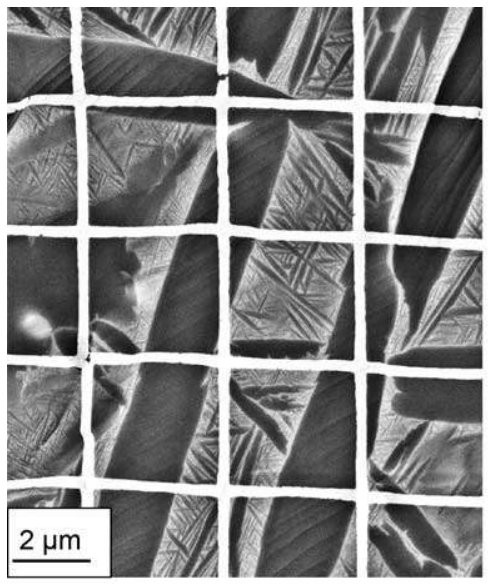

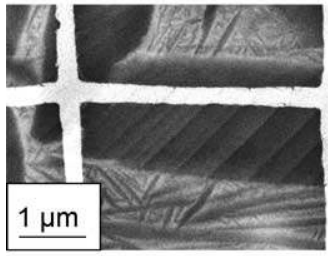

(a)
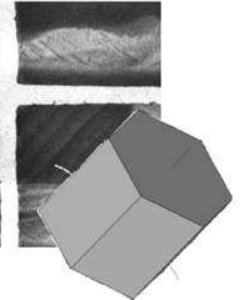

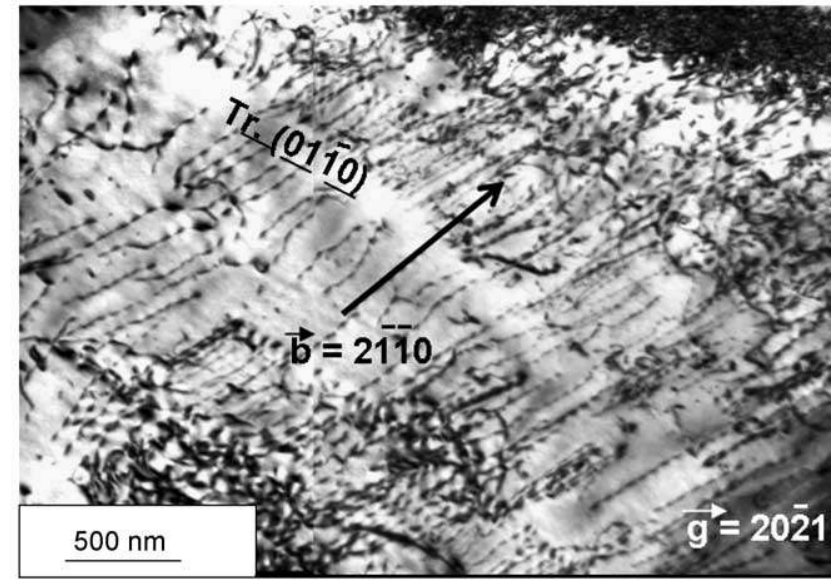

(b)

Fig. 11. Deformation mechanisms of the base metal: (a) SEM; (b) TEM.

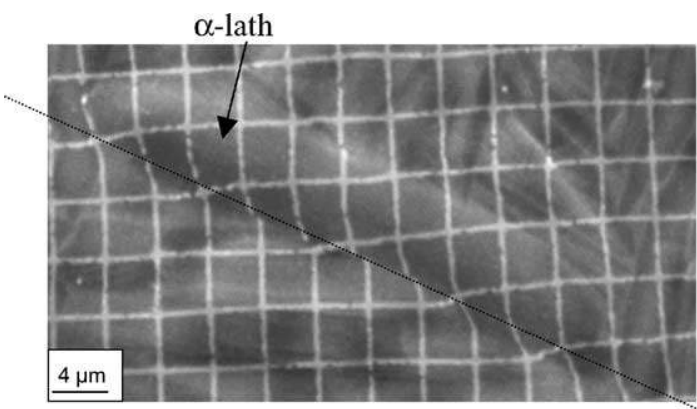

(a)

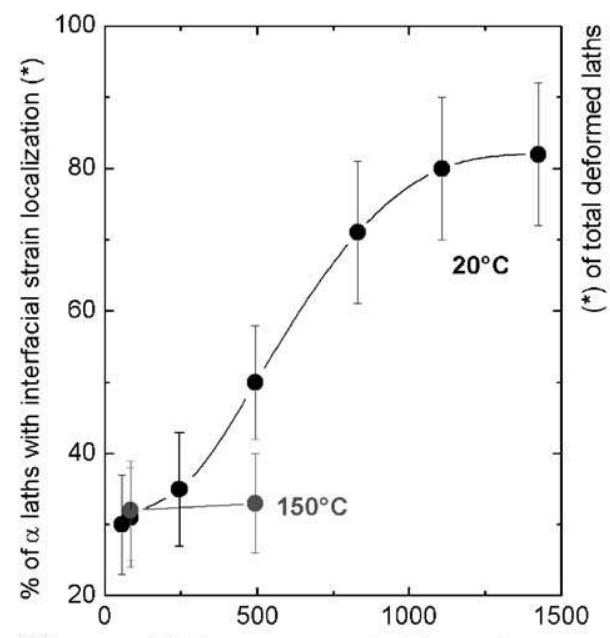

(b)

Fig. 12. Deformation mechanism of Ti6246 charged with hydrogen: (a) SEM observation; (b) influence of the $\mathrm{H}$ content on the amount of interfacial glide at 20 and $150^{\circ} \mathrm{C}$. the bonds between the two phases. But the distortion of the microgrids in a thin layer inside the $\alpha$-lath neighbouring the $\alpha / \beta$ interface on Fig. 12a suggests that intense sliding has occurred there. This observation seems to support the mechanism of hydrogen-enhanced localised plastic deformation described by Shih et al. for $\alpha$ titanium [20] rather than Margolin's explanation. At room temperature, hydrogen probably resides mainly in the $\beta$-phase where its solubility is very high. It could trigger dislocation emission from $\alpha / \beta$ interfaces into the $\alpha$-phase and enhance their mobility, finally leading to ductile decohesion along slip planes of the $\alpha$-phase close to the interface.

Magnin et al. [32], as well as Birnbaum et al. [33], relate the $\mathrm{H}$-enhanced localised plastic deformation of fcc metals to $\mathrm{H}$ shielding the interactions between dislocation segments of edge character making cross-slip more difficult. Such an explanation seems less appropriate for hcp and bcc metals, whose deformation is mainly controlled by screw dislocation glide. Shih et al. [20] as well as Senkov and Jonas [18], suggest that hydrogen, which is by far the most mobile interstitial, segregates preferentially around dislocations and shields their interactions with the other solute atoms mentioned earlier. Birnbaum et al. [33] observed that the $\mathrm{H}$-induced dislocation mobility enhancement in bcc iron (in which the thermally activated constriction of screw dislocations core also controls plastic flow) increases as the interstitial carbon content increases. Senkov and Jonas [18] show that the softening effect of hydrogen in $\alpha$ titanium is maximum in temperature and strain-range ranges for which dynamic strain ageing caused by $\mathrm{O}, \mathrm{N}, \mathrm{C}$ and Fe occurs in the hydrogen-free metal. 
Tensile tests performed at $150^{\circ} \mathrm{C}$ (Fig. 11) have shown that the hardening rate is higher than at room temperature (this leading to a higher uniform strain: $11 \%$ instead of $7.2 \%)$, that the strain rate sensitivity is almost zero and that charging with 500 ppmw $\mathrm{H}$ does not change the stress-strain curve at all, at this temperature.

\subsection{Influence of the hydrogen content on the creep behaviour}

Creep tests were performed at $20^{\circ} \mathrm{C}$ under a stress of $1000 \mathrm{MPa}$, representative of the stress level ahead of the crack tip, at high $K_{\max }$, as shown further (Fig. 13a). Creep is significant in the base metal where the creep strain (total strain minus initial strain at the end of loading ramp) reaches $1.6 \%$ within $100 \mathrm{~h}$. Fig. 13b shows
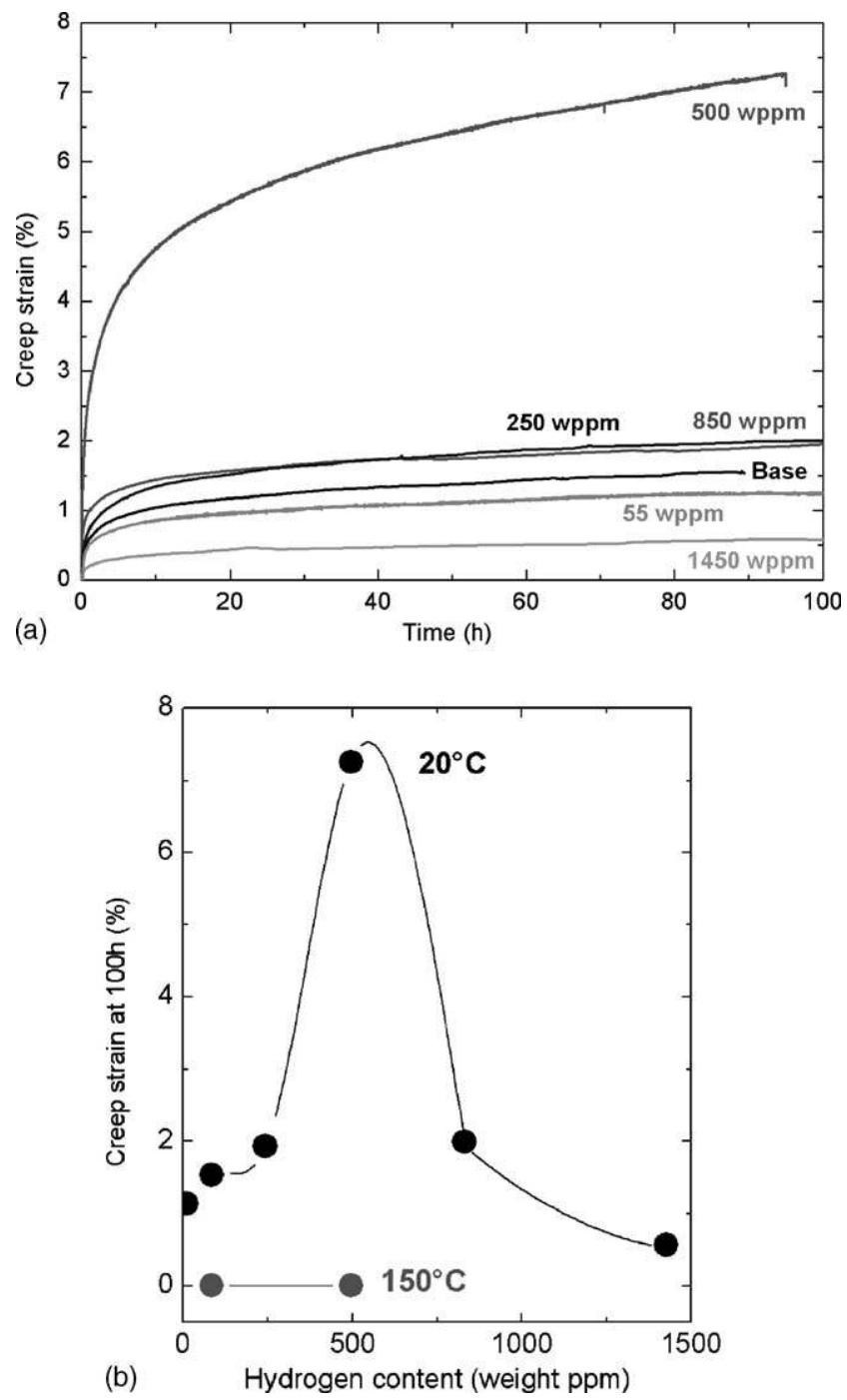

Fig. 13. Influence of the hydrogen content on the creep properties of Ti6246: (a) creep curves at $1000 \mathrm{MPa}$ and $20^{\circ} \mathrm{C}$; (b) evolution of the creep strain (total strain minus initial strain at the end of loading ramp) after $100 \mathrm{~h}$, at 20 and $150^{\circ} \mathrm{C}$ (under 1000 and $820 \mathrm{MPa}$, respectively) with the $\mathrm{H}$ content.

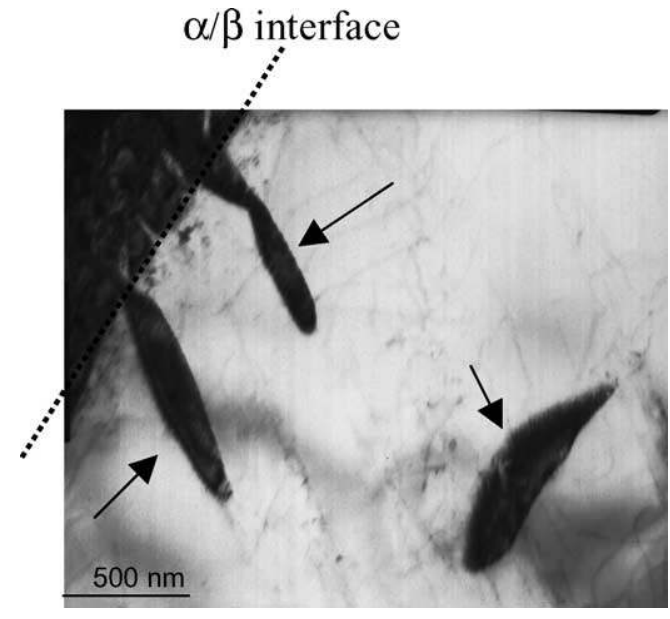

Fig. 14. TEM observation on a specimen charged at $1500 \mathrm{ppmw} \mathrm{H}$ and crept at $20^{\circ} \mathrm{C}$ under $1000 \mathrm{MPa}$.

that as the $\mathrm{H}$ content increases, the creep strain accumulated after $100 \mathrm{~h}$ first increases quite substantially (7\% for $486 \mathrm{ppmw} \mathrm{H}$ ) and then decreases. Gao and Dexter [10] as well as Hardie and Ouyang [8] similarly reported hydrogen-enhanced room-temperature creep in Ti-6Al-4V for $\mathrm{H}$ contents ranging from 80 to 720 and 30 to $500 \mathrm{ppmw}$, respectively.

As concerns the decrease in the accumulated creep strain and the parallel decrease in the total strain at fracture for a $\mathrm{H}$ content above 500 ppmw, two explanations can be envisaged, in direct relation with TEM observations on a specimen charged at $1450 \mathrm{ppmw} \mathrm{H}$ and crept under $1000 \mathrm{MPa}$ at room temperature, that have revealed the presence of particles in the $\alpha$-phase close to an $\alpha / \beta$ interface (Fig. 14) whose precise nature is still unknown. These particles might be hydrides or outgrowth of the $\beta$-matrix into the $\alpha$-lath, owing to the $\beta$-stabilising character of the $\mathrm{H}$ added in substantial quantity, as mentioned by Huez [22]. Both possibilities would be coherent with an inversion of the tendency for enhanced creep and ductility observed at lower $\mathrm{H}$ concentrations. More observations are necessary to conclude on that point.

Creep tests performed at $150{ }^{\circ} \mathrm{C}$ at a stress level homologous to $1000 \mathrm{MPa}$ in terms of $\sigma / \mathrm{UTS}$ (i.e. $820 \mathrm{MPa}$ ) have shown that at this temperature, the base metal does not creep at all and that the metal charged at $500 \mathrm{ppmw} \mathrm{H}$ does not creep either (under $840 \mathrm{MPa}$ ). This is consistent with several works from the literature reviewed by Conrad [15] who reports that the stress to cause a creep rate of $3 \times 10^{-10} \mathrm{~s}^{-1}$ in commercial titanium decreases as the temperature is raised from room-temperature to $350 \mathrm{~K}$, then increases with further rise in temperature, reaching a maximum at about $475 \mathrm{~K}$, decreasing again at higher temperature.

This is also in line with previous results by Jousset et al. [9] on Ti6242-Si. Under homologous stress levels, they observed tertiary creep at $20^{\circ} \mathrm{C}$, only primary creep at $150^{\circ} \mathrm{C}$ and no creep at all at $300^{\circ} \mathrm{C}$. They attributed 
this to dynamic strain ageing. In the present case, DSA may be the reason for the inhibition of creep at $150{ }^{\circ} \mathrm{C}$ and this would be coherent with the drop of the strain rate sensitivity. While several authors (Garde et al. [16], Doner and Conrad [17], Senkov and Jonas [18]) agree to attribute the "high-temperature" (HT)-DSA of $\alpha$ Ti (that is above $330^{\circ} \mathrm{C}$ ) to oxygen nitrogen, carbon and iron, it is more difficult to explain the "low-temperature" (LT)-DSA owing to the small volume diffusivity of these species. That is why Nemat-Nasser et al. [19] recently suggested that HT-DSA in $\alpha$ titanium is due to volume diffusion of $\mathrm{O}, \mathrm{N}$ and $\mathrm{C}$ while LT-DSA is due to their fast diffusion through the core of dislocations.

However, DSA is not the only possible explanation of creep inhibition at $150^{\circ} \mathrm{C}$. According to Naka et al. [28], there is a hardening mechanism in $\alpha$ titanium, which is active only between 130 and $330^{\circ} \mathrm{C}$ : the pinning of dislocations by sessile jogs formed by double cross-slip from (to) prismatic to (from) first-order pyramidal planes and the formation of many dipoles. On the other hand, Farenc et al. [29,30] have shown that in $\alpha$ titanium, rectilinear screw dislocations move by jumps between locking positions and that the decrease in jump-length as the temperature increases leads to several transitions in the mechanisms that control dislocation propagation. These transitions could explain the anomaly in the temperature dependence of the tensile and creep strength in the range $300-500 \mathrm{~K}$.

\section{Numerical study}

The simulations described further constitute a first estimate of stress and strain fields at the crack tip and no attempt was made yet to describe hydrogen transport and its influence on the material behaviour. Such a study is, however, helpful for the understanding of some of the experimental observations described earlier.

Elastic-viscoplastic constitutive equations [34] were fitted to experimental stress-strain curves obtained at 20 and $150{ }^{\circ} \mathrm{C}$ for the base metal:

The total strain is the sum of an elastic and a viscoplastic term:

$\underline{\underline{\varepsilon}}=\underline{\underline{\varepsilon}}+\underline{\varepsilon}_{\mathrm{v} p}$.

The elastic term obeys Hooke's law:

$\underline{\underline{\varepsilon}}=\frac{1+v}{E} \underline{\underline{\sigma}}-\frac{v}{E} \operatorname{trace}(\underline{\underline{\sigma}}) \underline{\underline{I}}$.
The flow criterion is:

$f=J_{2}(\underline{\underline{\sigma}}-\underline{\underline{X}})-R \geq 0$,

where $J_{2}$ denotes the second invariant of the stress deviator and $\underline{X}$ denotes the sum of two non-linear kinematic hardening variables or "back stress" (the non-linear form is suitable for the description of ratchetting [34]):

$\underline{\underline{X}}=\underline{\underline{X}}_{1}+\underline{\underline{X}}_{2}, \quad \underline{\underline{X}}_{i}=\frac{2}{3} C_{i} \underline{\underline{\varepsilon}}_{\mathrm{vp}}-\gamma_{i} \underline{\underline{X}}_{i} \dot{p}, \quad i=1,2$.

$R$ denotes an isotropic hardening variable or "friction stress" (which describes the cyclic softening of this material):

$R=k_{0}+Q(1-\exp (-b p))$.

The flow rule is:

$\dot{\underline{\varepsilon}}_{\mathrm{vp}}=\dot{p} \frac{\partial f}{\partial \underline{\underline{\sigma}}}$, with $\dot{p}=\sqrt{\frac{2}{3} \dot{\varepsilon}_{\mathrm{v} p}: \dot{\underline{\varepsilon}}_{\mathrm{vp}}}=\left\langle\frac{f}{K}\right\rangle^{n}$,

where $\langle x\rangle$ denotes the positive part of $x$.

An optimisation program was used to fit the 11 constants ( $\left.E, v, K, n, k_{0}, Q, b, C_{1}, \gamma_{1}, C_{2}, \gamma_{2}\right)$ that appear in these equations (gathered in Table 1) to the stress-strain curves measured at 20 and $150{ }^{\circ} \mathrm{C}$ during tensile, cyclic or creep tests (more details can be found in [35]). Note also that an analysis of the relationship between the microstructure and constitutive equations of this alloy can be found in [26].

A mesh representing half a CT specimen was generated with eight nodes quadratic elements, $10 \mu \mathrm{m}$ wide close to the crack tip. A rise up to $K_{\max }=57 \mathrm{MPa} \mathrm{m}^{1 / 2}$ followed by cycles at $10 \mathrm{~Hz}$, at $\Delta K=2,6,9$ or $12 \mathrm{MPa} \mathrm{m}^{1 / 2}$ was simulated, with node release to simulate crack growth (the periodicity of this node release was adjusted so as to reproduce the measured crack growth rate for each $\Delta K$ ).

The profiles of von Mises equivalent stress along the ligament computed at 20 and $150^{\circ} \mathrm{C}$ are plotted in Fig. 15. The stress level is above $1000 \mathrm{MPa}$ over a distance of $50 \mu \mathrm{m}$ at room temperature and, as shown before, it is sufficient to induce creep in the base metal. By contrast, at $150{ }^{\circ} \mathrm{C}$, the von Mises equivalent stress does not exceed $600 \mathrm{MPa}$, which is quite insufficient to induce creep.

The stress/strain loops computed a few microns ahead of the crack tip indicate that for $\Delta K>6 \mathrm{MPa} \mathrm{m}^{1 / 2}$, reverse plastic deformation at unloading moderates forward strain accumulation due to creep (but for $\Delta K>12 \mathrm{MPam}^{1 / 2}$, ratchetting provides an additional mechanism for strain accumulation, since the loading cycle is quite asymmetrical). For $\Delta K=2 \mathrm{MPa} \mathrm{m}^{1 / 2}$, unloading is almost purely elastic

Table 1

Parameters used in the constitutive equations

\begin{tabular}{rrlllllllrrr}
\hline & $E(\mathrm{MPa})$ & $v$ & $k_{0}(\mathrm{MPa})$ & $Q(\mathrm{MPa})$ & $b$ & $K$ & $n$ & $C_{1}(\mathrm{MPa})$ & $\gamma_{1}$ & $C_{2}(\mathrm{MPa})$ & $\gamma_{2}$ \\
\hline $20^{\circ} \mathrm{C}$ & 109000 & 0.3 & 691 & -346 & 23 & 408 & 16 & 20000 & 44 & 142900 & 2828 \\
$150^{\circ} \mathrm{C}$ & 96000 & 0.3 & 641 & -6 & 100 & 132 & 14.6 & 15350 & 98 & 1237 & 0 \\
\hline
\end{tabular}




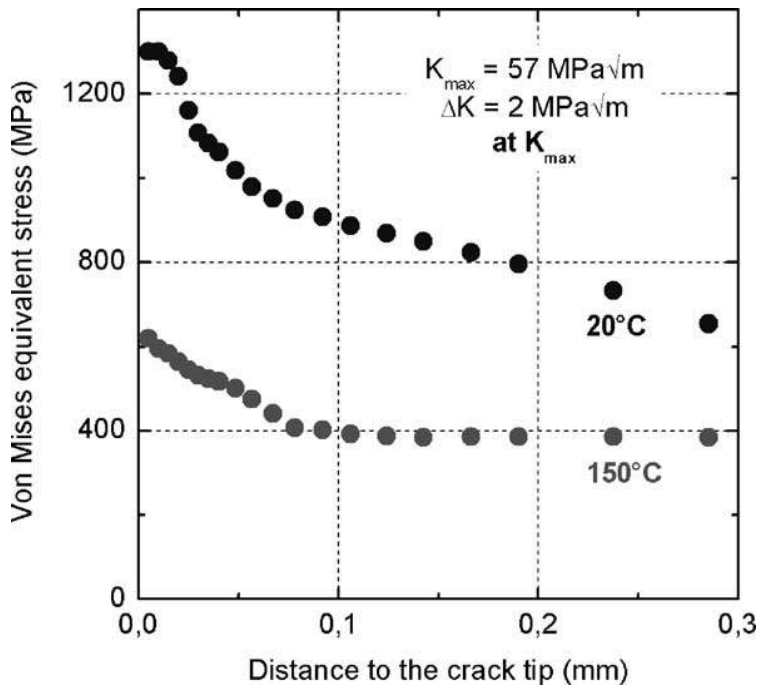

Fig. 15. FE simulations at $K_{\max }=57 \mathrm{MPam}^{1 / 2}$ : profile of von Mises equivalent stress along the ligament at 20 and $150^{\circ} \mathrm{C}$ at $K_{\max }$.

and thus not very efficient to moderate creep, which becomes dominant.

Fig. 16a compares the profile of the stress tensor trace along the ligament, 50 cycles after the last node release, for two $\Delta K$, at $20^{\circ} \mathrm{C}$. For $\Delta K=12 \mathrm{MPa} \mathrm{m}^{1 / 2}$, hydrostatic compression occurs at $K_{\min }$ over a significant distance ahead of the crack tip, whereas for $\Delta K=2 \mathrm{MPa} \mathrm{m}^{1 / 2}$, hydrostatic tension still prevails at unloading, except for a minute zone very close to the tip. Fig. 16b shows that the size of the zone that undergoes compression at each cycle vanishes as $\Delta K$ decreases. Since hydrogen diffusion in the lattice is driven by the gradient of its chemical potential, which is itself a linear function of the trace of the stress tensor [36], a small $\Delta K$ is thus more favourable to internal hydrogen diffusion to the immediate vicinity of the crack tip, which is permanently attractive for hydrogen instead of being alternatively attractive and repulsive. This is probably why a $\mathrm{H}$-enriched zone along the crack flanks has been detected by SIMS analyses only in the part grown below $\Delta K=$ $3 \mathrm{MPa} \mathrm{m}^{1 / 2}$.

Comparisons of stress and strain states at 20 and $150{ }^{\circ} \mathrm{C}$ show that the crack tip is more blunted, and the trace of the stress tensor at $150{ }^{\circ} \mathrm{C}$ is half that at room temperature, making the tip less attractive for hydrogen.

The incubation period for sustained load cracking after cyclic loading observed at $20^{\circ} \mathrm{C}$ (Fig. 2b) might correspond to the time necessary to reach a sufficient hydrogen concentration at the very crack tip, to trigger creep and interfacial localisation. The smaller the last $\Delta K$ applied, the smaller the zone under triaxial compression, repulsive for $\mathrm{H}$ at unloading and thus the shorter the distance that hydrogen, segregated beyond this zone, in the zone of hydrostatic tension has to travel to reach the tip. The consequence is a shorter incubation period, in accordance with experimental data. With a hydrogen diffusivity between $1.3 \times 10^{-10}$ and $1.6 \times 10^{-10} \mathrm{~cm}^{2} / \mathrm{s}$ (which is the order of magnitude found in the literature for $\alpha$ Ti at $20^{\circ} \mathrm{C}$ ) the diffusion distance $\sqrt{D t}$ would correspond to the size of the zone in periodic compression for $\Delta K=3,4$ or $6 \mathrm{MPa} \mathrm{m}^{1 / 2}$ (i.e. 3.8, 5 and $7 \mu \mathrm{m}$ ), if the time $t$ is set equal to the corresponding incubation periods (i.e. 900,1800 and $3600 \mathrm{~s})$.
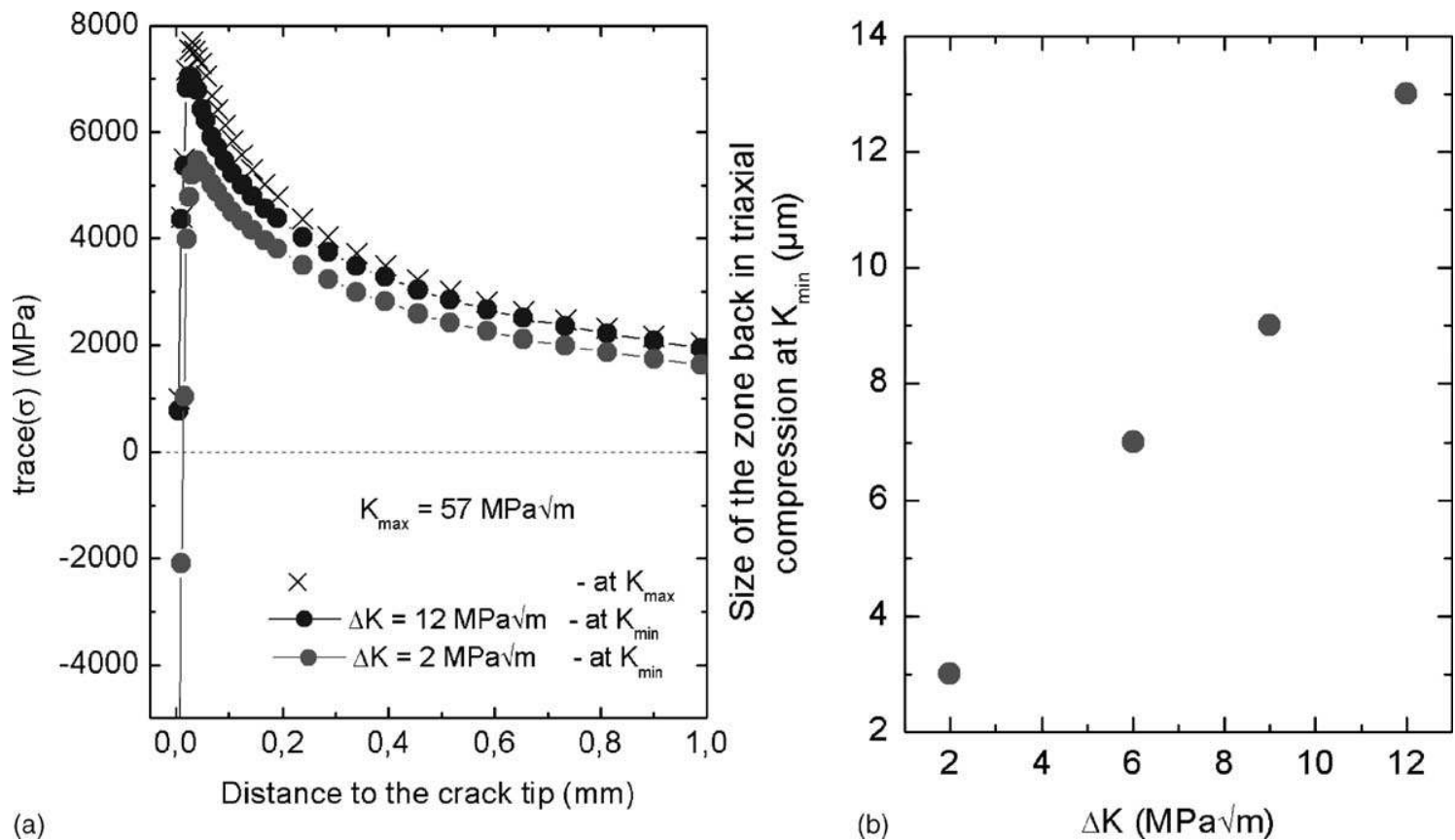

Fig. 16. FE simulations for $K_{\max }=57 \mathrm{MPa} \mathrm{m}^{1 / 2}$ at $20^{\circ} \mathrm{C}$ : (a) profile of the trace of the stress tensor along the ligament at $K_{\max }$ and $K_{\min }$ for $\Delta K=2$ or $12 \mathrm{MPam}^{1 / 2}$; (b) size of the zone ahead of the crack tip in triaxial compression at $K_{\min }$ as a function of $\Delta K$. 


\section{Summary and concluding remarks}

At high $K_{\max }$, creep has been shown (through direct SEM observations and through FE simulations) to occur around the crack tip at $20^{\circ} \mathrm{C}$ in the base metal. SIMS analysis proved that $\mathrm{H}$ concentrates at the tip by a factor of two. Tests have shown that a few hundred ppm hydrogen trigger room-temperature creep, probably by shielding the interactions of screw dislocations with hardening interstials $(\mathrm{O}, \mathrm{C}$ and $\mathrm{N}$ ) and edge dislocations mutual interactions. Hydrogen is also responsible for strain localisation at $\alpha / \beta$ interfaces and ductile decohesion along slip planes in the $\alpha$-laths very close to interfaces. The abnormal cracking regime at high $K_{\max }$ observed at $20^{\circ} \mathrm{C}$ seems thus to be due to $\mathrm{H}$-assisted creep.

At $150{ }^{\circ} \mathrm{C}$ the alloy, even enriched with $\mathrm{H}$, does not creep. As a consequence, no abnormal cracking regime is observed at this temperature.

In the present study, no creep tests have been performed on Ti6246 at $500{ }^{\circ} \mathrm{C}$ (a temperature for which the abnormal cracking regime exists, although 10 times slower than at $20^{\circ} \mathrm{C}$ for the same $K_{\max }$, see Fig. 2a). However, tests performed by Bourgeois [21] on the same alloy processed under the same conditions show that secondary creep occurs at $500^{\circ} \mathrm{C}$ for a stress of $540 \mathrm{MPa}$ and tertiary creep for $580 \mathrm{MPa}$. These stress levels are likely to be reached at the crack tip and creep might thus explain the abnormal cracking at this temperature, as well as at room temperature.

\section{Acknowledgements}

The authors wish to acknowledge the contributions of Dr. Louis Raimbault from CIG, ENSMP for SIMS analyses, Dr. Mustapha Jouiad from LMPM, ENSMA for TEM observations and Dr. A.M. Brass from LPCES, Paris-Sud university for hydrogen content measurements.

\section{References}

[1] W.A. Herman, R.W. Hertzberg, R. Jaccard, Fatigue Fract. Eng. Mater. Struct. 11 (1988) 303.

[2] P.S. Pao, D.A. Meyn, R.A. Bayles, C.R. Feng, Scripta Metall. Mater. 33 (1995) 497.
[3] M. Lang, G.A. Hartman, J.M. Larsen, Scripta Mater. 38 (1998) 1803.

[4] C. Sarrazin-Baudoux, Y. Chabanne, J. Petit, Scripta Mater. 40 (1999) 451.

[5] M. Lang, Acta Mater. 47 (1999) 3247.

[6] D.N. Williams, Mater. Sci. Eng. 24 (1976) 53.

[7] A. Vassel, J. Less Common Met. 69 (1980) 293

[8] D. Hardie, S. Ouyang, Corros. Sci. 41 (1999) 155.

[9] H. Jousset, L. Rémy, J.L. Strudel, in: Ellyin, Provan (Eds.), ICM8, vol. 2, Fleming Printing Ltd., 1999, p. 580.

[10] G.Y. Gao, S.C. Dexter, Metall. Trans. 18A (1987) 1125.

[11] T. Neeraj, D.H. Hou, G.S. Daehn, M.J. Mills, Acta Mater. 48 (2000) 1225.

[12] S. Ankem, C.A. Green, S. Singh, Scripta Metall. Mater. 30 (1994) 803.

[13] D. Doraiswamy, S. Ankem, Acta Mater. 51 (2003) 1607.

[14] B.C. Odegard, A.W. Thompson, Metall. Trans. 5 (1974) 1207.

[15] H. Conrad, Prog. Mater. Sci. 26 (1981) 123.

[16] A.M. Garde, A.T. Santhanan, R.E. Reed-Hill, Acta Metall. 20 (1972) 213.

[17] M. Doner, H. Conrad, Metall. Trans. 4 (1973) 2809.

[18] O.N. Senkov, J.J. Jonas, Metall. Trans. 27A (1996) 1877.

[19] S. Nemat-Nasser, W.G. Guo, J.Y. Cheng, Acta Metall. 47 (1999) 3705.

[20] D. Shih, I.M. Robertson, H.K. Birnbaum, Acta Metall. 36 (1988) 111.

[21] M. Bourgeois, Ph.D. thesis, Université de Technologie de Compiègne, France, 1997.

[22] J. Huez, Ph.D. thesis, Université de Technologie de Compiègne, France, 1996.

[23] S. Ankem, H. Margolin, Metall. Trans. 13A (1982) 267.

[24] L. Allais, M. Bornert, T. Bretheau, D. Caldemaison, Acta Metall. Mater. 42 (1994) 3865.

[25] Y. Guillot, M. Clavel, X. Feaugas, Scripta Mater. 44 (2001) 1011.

[26] X. Feaugas, M. Clavel, Acta Mater. 7 (1997) 2685.

[27] H. Suri, G.S. Neeraj, D.H. Hou, J.M. Scott, J. Mills, Mater. Sci. Eng. A 234 (2001) 996.

[28] S. Naka, L.P. Kubin, C. Perrier, Philos. Mag. A 63 (1991) 1035.

[29] S. Farenc, D. Caillard, A. Couret, Acta Metall. Mater. 41 (1993) 2701.

[30] S. Farenc, D. Caillard, A. Couret, Acta Metall. Mater. 43 (1995) 3669.

[31] H. Margolin, Scripta Metall. Mater. 24 (1990) 2397.

[32] T. Magnin, C. Bosch, K. Wolski, D. Delafosse, Mater. Sci. Eng. A 314 (2001) 7.

[33] H.K. Birnbaum, I.M. Robertson, P. Sofronis, in: J. Lepinoux (Ed.), Multiscale Phenomena in Plasticity, Kluwer Academic Publishers, 2000, p. 367.

[34] J. Lemaitre, J.L. Chaboche, Mécanique des Matériaux Solides, Dunod, Paris, 1988.

[35] F. Mignot, Ph.D. thesis, Ecole Polytechnique, Palaiseau, 2003.

[36] J.C.M. Li, R.A. Oriani, L.S. Darken, Z. Phys. Chem. Neue Folge 49 (1966) 271 